\title{
A STUDY OF IMMEDIATE IMPLANT PLACEMENT IN FRESH EXTRACTION SOCKET
}

\author{
Sriharsha Konuru1, Syed Asimuddin², Venkateshwara Reddy33, Haranadha Reddy4, Sekhar Reddy5, Siva Prasada Reddy ${ }^{6}$ \\ ${ }^{1}$ Assistant Professor, Department of Dentistry, Maheshwara Medical College and Hospital, Patancheru, Telangana, India. \\ ${ }^{2}$ Assistant Professor, Department of Dentistry, Government Medical College and Hospital, Siddipet, Telangana, India. \\ 3 Professor and HOD, Department of Oral and Maxillofacial Surgery, Panineeya Mahavidyalaya Institute of Dental Sciences and \\ Research Centre, Hyderabad, Telangana, India. \\ ${ }^{4}$ Professor, Department of Oral and Maxillofacial Surgery, Panineeya Mahavidyalaya Institute of Dental Sciences and Research Centre, \\ Hyderabad, Telangana, India. \\ 5Professor, Department of Oral and Maxillofacial Surgery, Panineeya Mahavidyalaya Institute of Dental Sciences and Research Centre, \\ Hyderabad, Telangana, India. \\ ${ }^{6}$ Professor, Department of Oral and Maxillofacial Surgery, Panineeya Mahavidyalaya Institute of Dental Sciences and Research Centre, \\ Hyderabad, Telangana, India.
}

\section{BACKGROUND}

ABSTRACT

Missing teeth and supporting oral tissues have traditionally been replaced with dentures or bridges permitting restoration of mastication, speech, and aesthetics. Dental Implants are inserted into the jawbones to support prosthesis and are retained because of the intimacy of bone growth on their surface. This direct structural and functional connection between living bone and implant surface is termed as osseointegration.

Design- A prospective observational study on 20 patients undergoing extraction and immediate implant placement was carried out in the Department of Oral and Maxillofacial Surgery, Panineeya Mahavidyalaya Institute of Dental Sciences and Research Centre, Hyderabad, from May 2011 to April 2013 with a minimum Post Op follow up of six months.

\section{MATERIALS AND METHODS}

20 cases were selected during 2 years period May 2011 to April 2013 with various indications for extractions. Patients' records were kept for demographics and 6 months follow up period was included in the study. Evaluation was done among implants complications and patients satisfaction following surgery. Data was statistically analysed and presented.

\section{RESULTS}

Assessment was done clinically and radiographically at the following intervals; preoperatively (pre-op/baseline), at one month $(1 \mathrm{M})$, three months $(3 \mathrm{M})$ and six months $(6 \mathrm{M})$. Statistical analysis was performed to evaluate the changes at various time intervals. No significant complications were noted except for mild swelling, pain and gingival erythema which persisted for 5 days; exposure of implant healing screw was observed in 3 cases. Most of the patients were satisfied and happy with the results.

\section{CONCLUSION}

Immediate implants placed in fresh extraction sockets often produce good results with good functional outcome. Minimally invasive surgical technique, ease of procedure proper case selection and meticulous postoperative care preceded by good surgical and prosthetic protocol are the essentials for success.

\section{KEY WORDS}

Atraumatic Extraction, Immediate Implant Placement, GBR, Primary Stability, BMP, Osseointegration.

HOW TO CITE THIS ARTICLE: Konuru S, Asimuddin S, Reddy V, et al. A study of immediate implant placement in fresh extraction socket. J. Evolution Med. Dent. Sci. 2019;8(08):489-493, DOI: 10.14260/jemds/2019/109

\section{BACKGROUND}

Missing teeth and supporting oral tissues have traditionally been replaced with dentures or bridges permitting restoration of mastication, speech, and aesthetics. Dental implants offer an alternative. These implants are inserted into the jawbones to support a dental prosthesis and are retained because of the intimacy of bone growth on to their surface.

'Financial or Other Competing Interest': None.

Submission 19-11-2018, Peer Review 08-02-2019,

Acceptance 14-02-2019, Published 25-02-2019.

Corresponding Author:

Syed Asimuddin,

H. No. 12-2-831/24/25, Flat No. 103,

Mayfair Residency, MIGH Colony, Mehdipatnam,

Hyderabad-500028, Telangana, India.

E-mail: sayasim@gmail.com

DOI: $10.14260 /$ jemds $/ 2019 / 109$
This direct structural and functional connection between living bone and implant surface, termed osseointegration, was first described by Branemark 1977 and has undoubtedly been one of the most significant scientific breakthroughs in dentistry over the past 30 years. ${ }^{1}$

Manufacturers have designed specific implant systems to be used as immediate implants having various troncoconical shapes and different diameters in order to be used in sockets of varying dimensions. ${ }^{2}$

Since alveolar bone will remodel after tooth extraction, the degree of bone resorption is difficult to predict and could leave some portion of the implants exposed, determining a poor aesthetic outcome. In order to prevent this problem it has been suggested to augment the socket just after implant placement using various bone augmentation techniques such as autogenous bone grafts, bone substitutes, ${ }^{3,4}$ guided bone regeneration (GBR) with resorbable5,6 or non-resorbable barriers, and various bone promoting molecules such as 
enamel matrix derivative, ${ }^{7}$ platelet rich plasma (PRP), growth factors and bone morphogenetic proteins (BMPs) in order to accelerate and increment bone formation.

\section{MATERIALS AND METHODS}

A Prospective observational study on "Immediate placement of implants in fresh extraction sockets" was conducted in the Department of Oral and Maxillofacial Surgery, Panineeya Mahavidyalaya Institute of Dental Sciences and Research centre, Hyderabad, from May 2011 to April 2013. Approval from the local ethical committee was obtained. Twenty patients 15 males and 5 females between the ages of 20 to 45 years who needed restoration of the missing teeth immediately after extraction were randomly selected for the study.

\section{Inclusion Criteria}

1. Teeth with endodontic failures.

2. Grossly decayed teeth with partially lost crown structure and without radiographic evidence of periapical pathology.

3. Grossly decayed teeth with complete loss of crown structure and without periapical pathology.

4. Tooth lost due to trauma with intact alveolar socket.

\section{Exclusion Criteria}

- $\quad$ Patients with poor oral hygiene.

- Acute inflammatory, exacerbating processes.

- $\quad$ Presence of systemic conditions affecting healing such as uncontrolled diabetes, osteoporosis.

- Habitual smokers.

- Pregnant women.

- Patients suffering from blood dyscrasias.

A detailed case history and informed consent of each patient was obtained after explaining about the procedure and possible complications associated with it.

Intra oral periapical radiographs were taken for radiological evaluation before and implant placement. The radiographs were made with $\mathrm{E}$ speed films (KODAK). These films were exposed by using a XCP cone instrument with exposure factors according to a standard protocol. All the radiographs were taken by an experienced radiographic technician using paralleling cone technique. The development of the films was done manually in freshly prepared solutions. The time and temperature for developing and fixing was kept constant each time.

The patients were kept on peri-operative antibiotics. The antibiotics chosen were oral Amoxicillin ( $500 \mathrm{mg}$ ) given eight hourly. Oral Erythromycin (500 mg) was the antibiotic of choice for patients allergic to Penicillin. Pain control was achieved with appropriate analgesics.

\section{Surgical Technique}

The surgical procedure was performed under local anaesthesia using 2\% Lignocaine hydrochloride with adrenaline $(1: 80,000)$, under aseptic conditions. A preoperative chlorhexidine mouth wash was recommended. After administration of local anaesthesia crevicular incision was given to expose the surgical site. Releasing incisions were given based upon the accessibility required so that it can be either a triangular or trapezoid flap. After flap was raised, the tooth was extracted atraumatically using luxators. After tooth requiring immediate replacement was extracted, using sequential drills the socket was enlarged adequate enough for placement of implant ADIN-TOUAREG-S root form implants, Hydroxyapatite Coated (Mfg: Adin Dental Implant Systems, Israel) in place of that particular missing tooth. Particulate hydroxyapatite synthetic bone graft (Sybograf-C) was added to all the cases depending upon the necessity.

Patients were reviewed after one month, three months, six months for evaluation. Ateach visit the patients were assessed for the following parameters pain, swelling, gingival erythema, draining sinus, mobility of Implant, Exposure of Implant, Peri Implant radiolucency, Bone levels on mesial and distal aspect.

\section{RESULTS}

Pain

The mean pain score preoperatively was $4.6+/-3.27$. Post operatively at one month it was $0+/-0.00$, at three months was $0+/-0.00$ and at six months it was $0+/-0.00$. The reduction of pain values at one month, three months and six months postoperatively as compared to preoperative values was statistically significant.

\begin{tabular}{|c|c|c|c|}
\hline Parameter & Time & Mean & SD \\
\hline \multirow{4}{*}{ Pain } & Preoperative & 4.6 & 3.27 \\
\cline { 2 - 4 } & 1 Month & 0 & 0.00 \\
\cline { 2 - 4 } & 3 Months & 0 & 0.00 \\
\cline { 2 - 4 } & 6 Months & 0 & 0.00 \\
\hline \multicolumn{3}{|c|}{ Table 1. Pain Results } \\
\hline
\end{tabular}

\section{Swelling}

All the patients had mild swelling which persisted for three to five days. However, after one month, three months and six months post operatively no swelling was seen in any of the patients $(n=20)$.

\begin{tabular}{|c|c|c|}
\hline Time & Absent & Present \\
\hline Pre-0p & 20 & 0 \\
\hline 1 Month & 20 & 0 \\
\hline 3 Months & 20 & 0 \\
\hline 6 Months & 20 & 0 \\
\hline \multicolumn{2}{|c|}{ Table 2. Swelling Results } \\
\hline
\end{tabular}

\section{Gingival Erythema}

Presence of gingival erythema was seen in three out of twenty patients where three patients had trauma resulting in loss of tooth structure. However, no erythematous changes was noted at one month, three months and six months post implant placement $(n=20)$.

\begin{tabular}{|c|c|c|}
\hline Time & Absent & Present \\
\hline Pre-0p & 17 & 3 \\
\hline 1 Month & 20 & 0 \\
\hline 3 Months & 20 & 0 \\
\hline 6 Months & 20 & 0 \\
\hline \multicolumn{2}{|c|}{ Table 3. Gingival Erythema Results } \\
\hline
\end{tabular}

\section{Draining Sinuses}

No patient had preoperative draining sinuses. After one month, three months and six months post implant insertion no draining sinuses were seen in any of the patients $(n=20)$. 


\section{Exposure of The Implant}

Exposure of the implant was seen in three cases out of twenty. In all the three cases healing screw was exposed one-month post implant insertion. Remaining seventeen implants had adequate soft tissue cover $(n=20)$.

\begin{tabular}{|c|c|c|}
\hline Time & Absent & Present \\
\hline Pre-Op & 20 & 0 \\
\hline 1 Month & 17 & 3 \\
\hline 3 Months & 20 & 0 \\
\hline 6 Months & 20 & 0 \\
\hline \multicolumn{2}{|c|}{ Table 4. Exposure of The Implant Results } \\
\hline
\end{tabular}

\section{Mobility of The Implant}

After one month, three months and six months post implant insertion, no mobility was seen in any of the patients $(n=20)$.

\section{Peri-Implant Radiolucency}

After one month, three months and six months post implant insertion, no peri-implant radiolucency was seen in any of the patients $(\mathrm{n}=20)$

\section{Bone Levels on Mesial and Distal Aspect of The Implant}

Bone levels on the mesial and distal aspects were assessed preoperatively, one month, three months and six months post implant insertion. The mean bone level (mesial aspect) score preoperatively was $0.86+/-0.37$. Post operatively at one month it was $0.95+/-0.20$, at 3 months was $0.85+/-0.22$ and at six months it was $0.77+/-0.39$. The mean bone level (distal aspect) score preoperatively was $0.94+/-0.35$. Post operatively at one month it was $0.96+/-0.29$, at three months was $0.95+/-0.26$ and at six months it was $0.71+/-0.47$. The bone level values at end of six months have shown no significant change compared to baseline values.

\begin{tabular}{|c|c|c|c|c|c|c|c|c|c|}
\hline $\begin{array}{l}\text { Sl. } \\
\text { No. }\end{array}$ & Parameters & $\begin{array}{r}\mathrm{F} \\
\text { Ope }\end{array}$ & $\begin{array}{l}\text { re } \\
\text { ative }\end{array}$ & $\begin{array}{r}1 \\
\text { Mor }\end{array}$ & nth & $\begin{array}{r}3 \\
\text { Mon }\end{array}$ & $\begin{array}{l}3 \\
\text { hths }\end{array}$ & $\begin{array}{r}6 \\
\text { Mon } \\
\end{array}$ & \begin{tabular}{|l|}
6 \\
nths
\end{tabular} \\
\hline & & $\mathbf{M}$ & S.D. & M & SID & $\mathbf{M}$ & S.D. & $\mathbf{M}$ & S.D. \\
\hline 1. & $\begin{array}{l}\text { Bone Levelson } \\
\text { Mesial } \\
\text { Aspect (in } \\
\text { millimeters) } \\
\end{array}$ & 0.86 & 0.37 & 0.95 & 0.20 & 0.85 & 0.22 & 0.77 & 0.39 \\
\hline 2.. & $\begin{array}{l}\text { Bone Levelson } \\
\text { Distal } \\
\text { Aspect (in } \\
\text { millimeters) }\end{array}$ & 0.94 & 0.35 & 0.96 & 0.29 & 0.95 & 0.26 & 0.71 & 0.47 \\
\hline
\end{tabular}

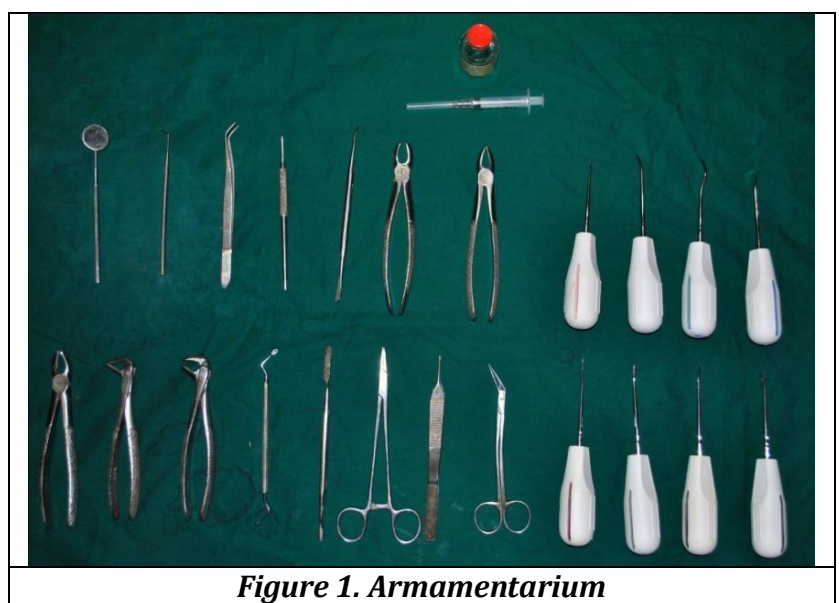

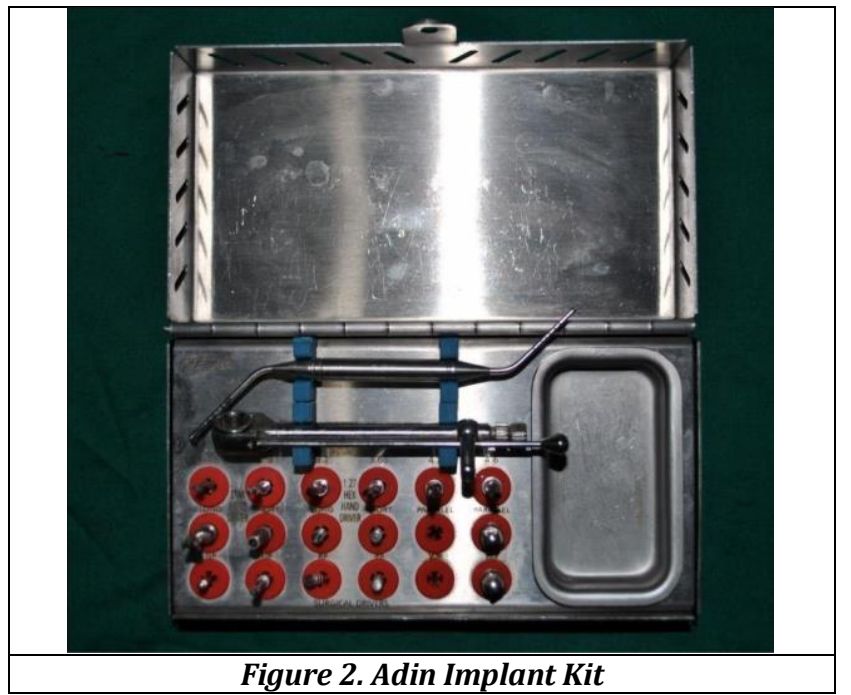
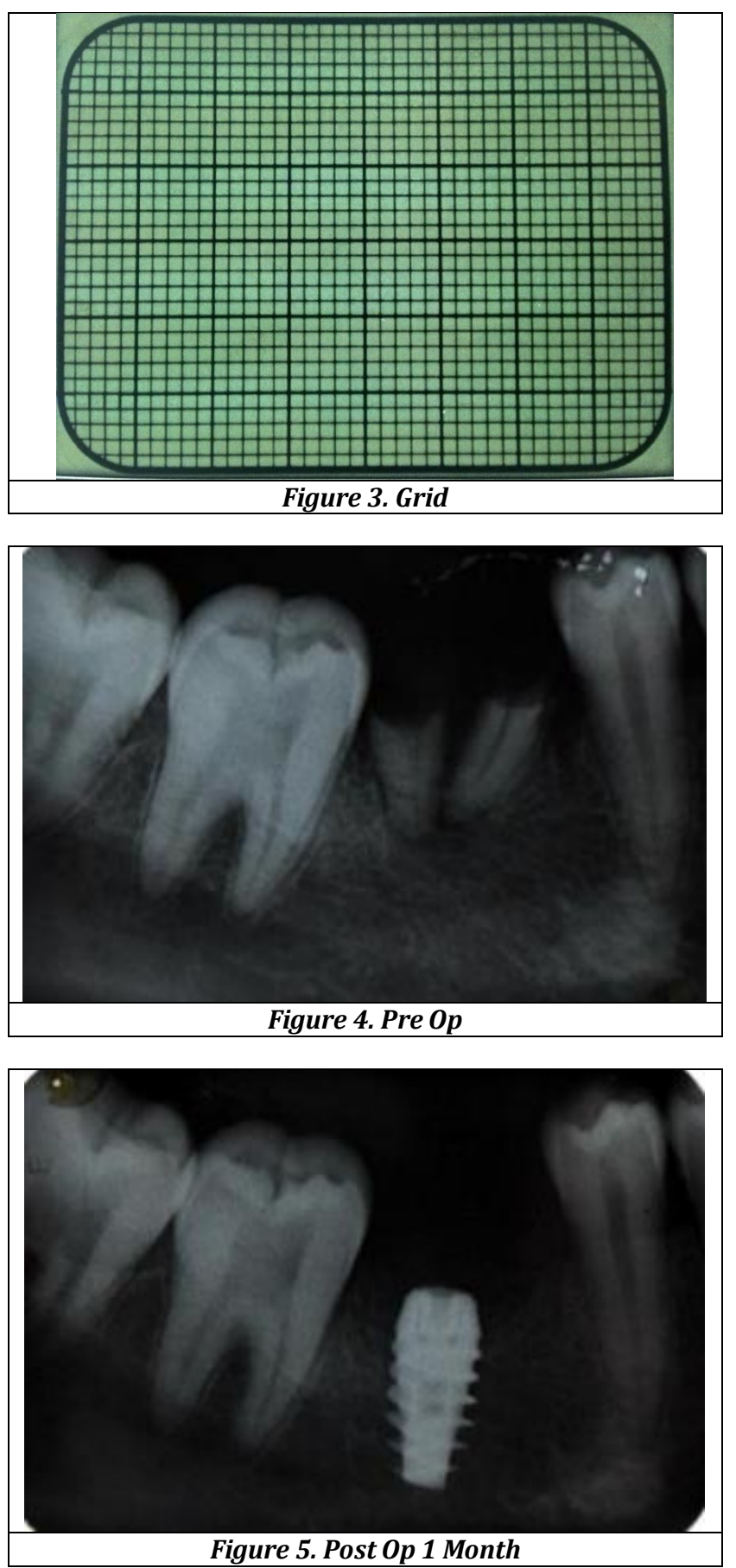

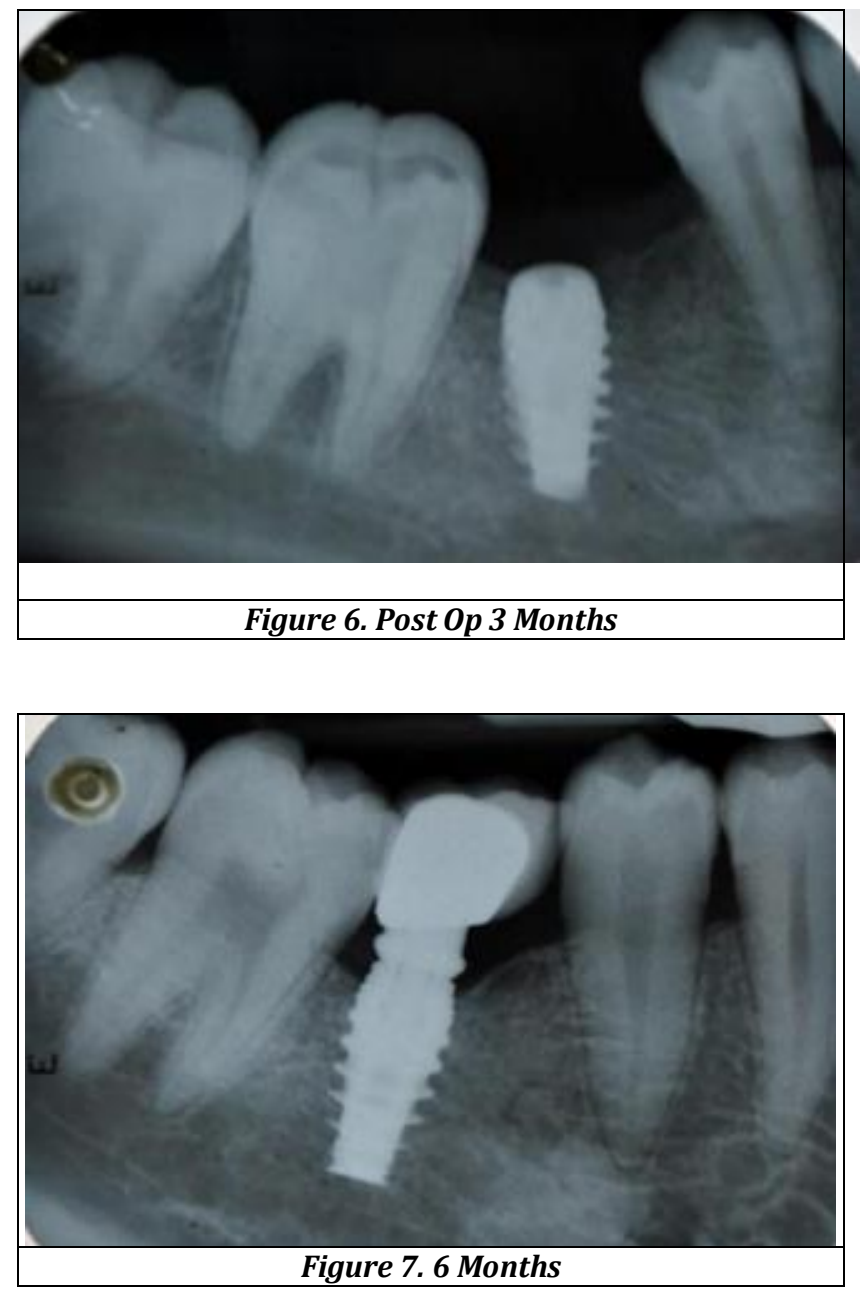

\section{DISCUSSION}

The goal of modern dentistry is to prevent tooth loss and to provide a healthy dentition with optimal functional efficiency, structural balance and aesthetic harmony. It was shown that after extraction of natural teeth, the greatest reduction of the alveolar bone occurs in the first six months to two years. 8,9 For this reason, within the last decades, the 'Gold standard' implant treatment protocol has been challenged by experiments, which aimed at shortening the treatment period and by reducing the number of surgical procedures. ${ }^{5} \mathrm{New}$ protocols have been developed in which implants are placed at the time of extraction of the tooth, known as immediate implants. ${ }^{10,11,12}$

Bone loss after tooth extraction remains an important issue. Anatomically, bone resorption occurs both buccolingually and apicocoronally, and the first 6 months post extraction are critical carrying the highest rate of bone resorption in either direction. ${ }^{13}$

The primary advantages of placing immediate implants are the reduction in time of therapy, reduction in surgical episodes, and preservation of the bone and gingival tissues. ${ }^{13,14,15}$ Greater rate of bone resorption occurs during the first six months following tooth extraction, unless an implant is placed, or a socket augmentation procedure performed. The early maintenance of the gingival form greatly facilitates the peri-implant gingival tissue esthetics by maintaining support for the interdental papillae.
Borosenquist et $\mathrm{al}^{16,17}$ evaluated various patients subjected to immediate implant placement after extraction and stated that osseointegration was the most important factor in determining the success of the implant. Apart from osseointegration any clinical signs of inflammation were also assessed. The found $96 \%$ success rates after immediate implant placement in fresh extraction sites.

Lars Schropp et al 18 in a study concluded that new bone formation occurs in infrabony defects associated with immediately placed implants in extraction sockets.

Radiographic evaluation of bone forms a very important and viable means of detecting health and stability of bone around the peri-implant hard tissue. In our study, none of the patients had preoperative peri-implant radiolucency. After one month, three months and six months post implant insertion, no peri-implant radiolucency was seen in any of the patients. Karthik. K, Sivakumar, Sivaraj, Thangaswamy V19 reviewed the criteria for success of implants post insertion and stated that peri-implant radiolucency is an important criterion for evaluation of implant success.

The radiographic evaluation was done on periapical films using the long cone technique using a millimetre marking Grid. Marjorie K. Jeffcoat ${ }^{120}$ had stated that periapical view is a useful view as it minimizes the distortion of the bone to root relationship while imaging the root apex. Bone levels on the mesial and distal aspects were assessed preoperatively, one month, three months and six months post implant insertion. The bone level values at end of six months have shown no significant change compared to baseline values preoperatively. Bone graft material was used in all the cases.

Studies by Kohal RJ et al, Tahemar S et al, Becker W et $\mathrm{al}^{21,22,23}$ claimed that patients whose implanted sockets were filled with bone graft material showed better results than patients who did not receive bone graft. Since in our study all the cases received bone graft material at time of implant placement, $100 \%$ success was seen without any failures. Primary stability in all the cases treated in this study was achieved.

However, the drawbacks of this study were the use of conventional radiographs for the interpretation and lack of Periotest. Perhaps a larger study on immediate implant placement with a long term follow up could help us acknowledge the merits and demerits of immediate placement of implants in fresh extraction socket.

\section{CONCLUSION}

The aim of dental implant treatment is to provide safe, predictable, and cost-effective tooth replacement therapy to patients. Minimally invasive surgical technique, ease of procedure and shorter time involved together with minimum post extraction complications are the important advantages of this method. However, proper case selection and meticulous postoperative care preceded by good surgical and prosthetic protocol are the essentials for success.

From this study it can be concluded that immediate implants placed in fresh extraction sockets often produce good results with good functional outcome.

\section{REFERENCES}

[1] Misch CE. Contemporary Implant Dentistry. 3rd edn. Mosby Elsevier Inc., 2008: p. 27. 
[2] Gomez-Roman G, Schulte W, d'Hoedt B, et al. The Frialit-2 implant system: five-year clinical experience in single-tooth and immediately postextraction applications. The International Journal of Oral and Maxillofacial Implants 1997;12(3):299-309.

[3] Block MS, Kent JN. Placement of endosseous implants into tooth extraction sites. Journal of Oral and Maxillofacial Surgery 1991;49(12):1269-76.

[4] Yukna RA. Clinical comparison of hydroxyapatitecoated titanium dental implants placed in fresh extraction sockets and healed sites. Journal of Periodontology 1991;62(7):468-72.

[5] Lazzara RJ. Immediate implant placement into extraction sites: surgical and restorative advantages. Int $\mathrm{J}$ Periodontics and Restorative Dentistry 1989;9(5):332-43.

[6] Becker W, Dahlin C, Becker BE, et al. The use of e-PTFE barrier membranes for bone promotion around titanium implants placed into extraction sockets: a prospective multicenter study. The International Journal of Oral and Maxillofacial Implants 1994;9(1):31-40.

[7] Cangini F, Cornelini R. A comparison between enamel matrix derivative and a bioabsorbable membrane to enhance healing around transmucosal immediate post-extraction implants. Journal of Periodontology 2005;76(10):1785-92.

[8] Carlsson GE, Persson G. Morphologic changes of the mandible after extraction and wearing of dentures. A longitudinal, clinical and X-ray cephalometric study covering 5 years. Odontologic Review 1967;18(1):2754.

[9] Araujo MG, Sukekava F, Wennstrom JL, et al. Ridge alterations following implant placement in fresh extraction sockets: an experimental study in the dog. Journal of Clinical Periodontology 2005;32(6):645-52.

[10] Watzek G, Haider R, Mensdorff-Pouilly N. Immediate and delayed implantation for complete restoration of the jaw following extraction of all residual teeth: a retrospective study comparing different types of serial immediate implantation. Int J Oral Maxillofac Implants 1995;10(5):561-7.

[11] Bhola M, Neely AL, Kolhatkar S. Immediate implant placement: clinical decisions, advantages and disadvantages. Journal of Prosthodontics 2008;17(7):576-81.

[12] Fugazzotto P. A retrospective analysis of immediately placed implants in 418 sites exhibiting periapical pathology: results and clinical considerations. Int J Oral Maxillofac Implants 2012;27(1):194-202.
[13] Covani U, Bortolaia C, Barone A, et al. Bucco-lingual crestal bone changes after immediate and delayed implant placement. Journal of Periodontology 2004;75(12):1605-12.

[14] Arlin ML. Immediate placement of osseointegrated dental implants into extraction sockets: advantages and case reports. Oral Health 1992;82(7):19-20, 23-4, 26.

[15] Barzilay I. Immediate implants: their current status. Int J Prosthodont 1993;6(2):169-75.

[16] Rosenquist B, Grenthe B. Immediate placement of implants into extraction sockets: implant survival. Int J Oral Maxillofac Implants 1996;11(2):205-9.

[17] Schwartz-Arad D, Chaushu G. Placement of implants into fresh extraction sites: 4 to 7 years retrospective evaluation of 95 immediate implants. J Periodontot 1997;68(11):1110-6.

[18] Schropp L, Kostopoulos L, Wenzel A. Bone healing following immediate versus delayed placement of titanium implants into extraction sockets: a prospective clinical study. Int J Oral Maxillofac Implants 2003;18(2):189-99.

[19] Karthik K, Sivakumar, Sivaraj, et al. Evaluation of implant success: a review of past and present concepts. J Pharm Bioall Sci 2013;5(Suppl 1):S117-S9.

[20] Jeffcoat MK. Radiographic methods for the detection of progressive alveolar bone loss. J Periodontal 1992;63(Suppl 4):367-72.

[21] Kohal RJ, Mellas P, Hurzeler MB, et al. The effects of guided bone regeneration and grafting on implants placed into immediate extraction sockets. An experimental study in dogs. J Periodontol 1998;69(8):927-37.

[22] Tehemar S, Hanes P, Sharawy M. Enhancement of osseointegration of implants placed into extraction sockets of healthy and periodontally diseased teeth by using graft material, an ePTFE membrane or a combination. Clin Implant Dent Relat Res 2003;5(3):193-211.

[23] Becker W, Schenk R, Higuchi K, et al. Variations in bone regeneration adjacent to implants augmented with barrier membranes alone or with demineralized freeze dried bone or autologous grafts: a study in dogs. Int J Oral Maxillofac Implants 1995;10(2):143-54. 